\title{
REGALISMO E INMUNIDAD ECLESIÁSTICA EN LA ESPAÑA DEL SIGLO XVIII: LA RESISTENCIA DEL CLERO VALENCIANO A LA IMPOSICIÓN DEL ESTANCO DEL TABACO ${ }^{1}$
}

\author{
RICARDO FRANCH BENAVENT \\ Universidad de Valencia
}

RESUMEN: El decreto de abolición de los fueros de los Reinos de Valencia y Aragón mantuvo vigente la normativa tradicional sobre la jurisdicción e inmunidad eclesiástica, ratificándose esta excepción en la Real Cédula de 7 de septiembre de 1707. Considerando que ello implicaba un reforzamiento de sus privilegios, los miembros de dicho estamento presentaron una intensa resistencia a la imposición del estanco del tabaco, que la monarquía contemplaba como una "regalía notoria" inherente a su soberanía. Inicialmente, la oposición fue asumida por la jerarquía eclesiástica y generó enfrentamientos jurisdiccionales de tal gravedad que Felipe $V$ procedió a la emisión de disposiciones de carácter regalista en las que se limitó seriamente los privilegios de la Iglesia valenciana. Pero, como los miembros del clero creyeron que estas medidas vulneraban sus derechos, se sintieron legitimados para adquirir el producto mediante la realización de actividades que la administración fiscal consideraba fraudulentas. El motín inducido por el clero en la localidad de Ayora en 1730 constituye la manifestación más evidente de la existencia de dicha mentalidad, que se mantuvo en gran medida durante el resto de la centuria.

PALABRAS ClAVE: Inmunidad eclesiástica. Regalismo. Fiscalidad. Fraude. Conflictividad. Tabaco. Valencia. siglo XVIII.

ABSTRACT: The charters abolition decree of the Kingdoms of Valencia and Aragon kept the traditional regulation on the jurisdiction and ecclesiastic immunity, and this excep-

1 Este trabajo se inscribe en el proyecto de investigación «Los conflictos generados por la abolición de los fueros en la sociedad valenciana del siglo XVIII» (GV05/072), financiado por la Consellería d`Empresa, Universitat i Ciència de la Generalitat Valenciana. 
tion was ratified in the Royal Order the $7^{\text {th }}$ of September in 1707. As the members of this class thought that it was implying a reinforcement of their privileges, they presented an intense resistance to the imposition of the tobacco monopoly, which the monarchy considered as a «well-known royalty» inberent in its sovereignty. Initially, the opposition was assumed by the ecclesiastic hierarchy and it generated jurisdictional conflicts so serious that Philip $V$ proceeded to the emission of dispositions in favour of his royal prerogative, which limited seriously the privileges of the $\mathrm{Va}$ lencian Church. But, as the clergy members believed that these dispositions were damaging their rights, they considered themselves legitimized to acquire the product by means of activities that the fiscal administration considered fraudulent. The riot induced by the clergy in Ayora's locality in 1730 constitutes the most evident manifestation of the mentioned mentality existence, which was kept during the rest of the century.

KEY WORDS: Ecclesiastical immunity. Royal prerogative. Tax system. Fraud. Conflict situations. Tobacco. Valencia. Eighteenth century.

Una de las peculiaridades fundamentales del regalismo borbónico fue la secularización de las bases jurídicas sobre las que dicha orientación política se sustentaba en la época de los Austrias, desvinculándose del poder delegativo del papa y presentándose como un derecho inherente a la soberanía real ${ }^{2}$. Esta evolución fue favorecida en los territorios de la Corona de Aragón por el considerable reforzamiento del poder monárquico que implicó el triunfo de la causa borbónica en la Guerra de Sucesión. No obstante, en el decreto de abolición de los fueros de los reinos de Valencia y Aragón que se emitió el 29 de junio de 1707 se excluyó expresamente la jurisdicción eclesiástica de la uniformización legislativa e institucional que se imponía en dichos territorios, proclamándose la voluntad de respetar el sistema anterior, avalado por las concordias ajustadas con la Santa Sede. El 29 de julio posterior, Felipe V reconocía, además, que la mayor parte de la nobleza y muchas comunidades, tanto laicas como eclesiásticas, habían permanecido fieles a su causa, por lo que eran recompensadas con el mantenimiento de los privilegios y exenciones de que gozaban. Si el principal fruto de este reconocimiento fue, para el primer estamento citado, la confirmación del privilegio alfonsino que se dispuso el 5 de noviembre de 1708, la disposición más trascendental para el clero fue la Real Cédula de 7 de septiembre de 1707 , en la que el monarca declaraba su voluntad de «...mantener la inmunidad de la Iglesia, personal y local, la jurisdicción eclesiástica y todas sus preeminencias en la posesión en que estaba la Iglesia en ambos Reinos antes de la pasada turbación...». Al sumarse a otras medidas favorables para los estamentos privilegiados, como la no aplicación de la Pragmática de reducción del

2 EGIDO, T.: «El regalismo y las relaciones Iglesia-Estado en el siglo XVIII», en GARCíA VILlosladA, R. (dir.), Historia de la Iglesia en España. Vol. IV, La Iglesia en la España de los siglos XVII y XVIII, Madrid, 1979, pp. 138-140. 
tipo de interés de los censales adoptada en Castilla en 1705 o la exención de las rentas señoriales y las propiedades eclesiásticas del nuevo impuesto del equivalente, aquellas disposiciones se han interpretado tradicionalmente como una muestra evidente de que el nuevo sistema político no resultó especialmente perjudicial para las clases elevadas. Sin embargo, P. Fernández Albaladejo ha insertado estas concesiones en el marco de la concepción «jurisdiccionalista» del poder que seguía manteniendo la monarquía, la cual le impulsaba al reconocimiento de los límites sociales que moderaban sus atribuciones. Pero ello no implicaba su renuncia al ejercicio de una serie de derechos que se consideraban privativos del monarca y que se derivaban directamente de su soberanía ${ }^{3}$. Así se aclaraba perfectamente en la Real Cédula de 7 de septiembre de 1707 anteriormente citada, ya que, tras proclamar el mantenimiento de la inmunidad y la jurisdicción eclesiástica, Felipe $\mathrm{V}$ declaraba también su voluntad de que se preservasen «...los demás fueros, usos y costumbres favorables a mis regalías y que limitan o moderan la jurisdicción e inmunidad eclesiástica...».

Entre las regalías de la Corona se encontraba su facultad de estancar la producción y comercialización de determinados productos o servicios con el fin de obtener unos ingresos extraordinarios en favor de la Real Hacienda. Aunque la creación de la mayoría de los estancos se produjo en la época de los Austrias, fue en el siglo XVIII cuando su aplicación se extendió a la mayor parte del territorio español, aprovechando la abolición de los fueros de los territorios de la Corona de Aragón, y sus recursos adquirieron una mayor trascendencia para las arcas de la monarquía. Ambas circunstancias suscitaron una intensa resistencia por parte del clero, ya que aquella tenía limitada su capacidad fiscal por la necesidad de solicitar el consentimiento papal de los nuevos servicios que se exigían al estamento eclesiástico, hallándose protegida su inmunidad por la bula de la Cena («In Coena Domini»), que castigaba con la imposición de la pena de excomunión a los oficiales reales que la vulnerasen. Sin embargo, dicha resistencia ha sido escasamente analizada por la historiografía. El conflicto más conocido es el liderado por el obispo de Cartagena, Luis Belluga, en contra del drástico incremento del precio de la sal que se decretó durante la Guerra de Sucesión, aunque el extenso memorial que imprimió al respecto en 1713 no ha sido prácticamente estudiado. El problema adquirió una intensa gravedad en la diócesis valenciana, al imbricarse con la oposición sostenida por ésta al cambio sustancial que implicaba la asunción por la administración real de los impuestos percibidos por la extinguida Generalitat ${ }^{4}$. Pero, al mismo tiempo, el clero

3 Fernández Albaladejo, P.: Fragmentos de monarquía. Trabajos de historia política. Madrid, 1992, pp. 356-360. Las diversas disposiciones aludidas en el texto, junto con la valoración de sus implicaciones en el sentido de que «...la situación fundamental de las clases altas no han empeorado con la mutación...», pueden verse en PESET ReIG, M.: «Notas sobre la abolición de los fueros de Valencia», en Anuario de historia del derecho español, T. 42, Madrid, 1972, pp. 657-715.

4 Franch BENAVENT, R.: «El cambio de naturaleza de las rentas de la Generalitat valenciana tras la abolición de los fueros: la reacción del clero en defensa de su inmunidad y los conflictos 
valenciano presentó también entonces una intensa resistencia a la imposición del estanco del tabaco. No en vano se trataba de un expediente fiscal novedoso, en la medida en que su introducción había tenido un carácter muy limitado durante el siglo XVII, siendo los municipios sus principales beneficiarios. Tras su asunción por la Corona durante la Guerra de Sucesión, sus ingresos experimentaron un crecimiento espectacular, llegando a equipararse a los generados por el equivalente en la década de 1780 y constituyendo, por tanto, uno de los pilares básicos sobre los que se sustentaba la fiscalidad exigida por la monarquía en el territorio valenciano en la segunda mitad de la centuria 5 . Ambas circunstancias son las que explican tanto la firme oposición presentada inicialmente por el clero valenciano a su introducción como el mantenimiento posterior del conflicto de forma larvada durante buena parte de la centuria.

provocados por la gestión de los intendentes», Estudis-31, Valencia, 2005, pp. 269-297. El memorial impreso en 1713 por el obispo Belluga llevaba el título de Memorial que da a Su Majestad el Obispo de Cartagena, Don Luis Belluga, de su Consejo, sobre los acrecimientos e impuestos en la sal. Una copia del mismo se halla en la Biblioteca del Colegio de Corpus Christi de Valencia (B.C.C.Ch.V.). Sig. 124-6/9. N $N^{\circ}$. En la reciente biografía que se ha realizado del personaje sólo se alude brevemente al mismo. Ver VILAR, J.B.: El cardenal Luis Belluga, Granada, 2001, pp. 118-119. Sobre el origen y evolución de la bula de la Cena, ver De La HerA, A.: «La Bula In Coena Domini. El derecho penal canónico en España y en las Indias», en MARTínez Ruiz, E. y Pi CORRALES, M. de P. (coords.), Instituciones de la España moderna. II. Dogmatismo e intolerancia, Madrid, 1997, pp. 71-87. La limitación de la capacidad fiscal de la monarquía sobre el clero en la época de los Austrias es subrayada por GELABERT, J.E.: «Guerra, fiscalismo y actividad económica en la España del siglo XVII», en ARANDA PÉreZ, F.J. (coord.), La declinación de la Monarquía Hispánica en el siglo XVII. Actas de la VII ${ }^{a}$ Reunión Científica de la Fundación Española de Historia Moderna, Cuenca, 2004, pp. 338-343. Sobre el origen y evolución de las rentas estancadas por la monarquía, ver ARTOLA, M.: La Hacienda del Antiguo Régimen. Madrid, 1982, pp. 98-106 y 287-294.

5 Franch BENAVENT, R y GimÉnez CHORnet, V.: «Una aproximación a la gestión territorial de la Real Hacienda: Las cuentas del Tesorero del Ejército de Valencia (1751-1807)», Estudis-29, Valencia, 2003, pp. 105-129. El estanco del tabaco ha suscitado numerosas investigaciones en los últimos años, entre las que pueden destacarse: COMÍN, F. y MARTín ACEÑA, P.: Tabacalera y el estanco del tabaco en España, 1636-1998, Madrid, 1999; GONZÁlez ENCISO, A. y TORRES SÁNCHEZ, R. (eds.): Tabaco y economía en el siglo XVIII, Pamplona, 1999; LuXÁN, S., SOlBES, S. y LAFORET, J.J. (eds.): El mercado del tabaco en España durante el siglo XVIII, Las Palmas de Gran Canaria, 2000; RodríGuez GoRdillo, J.M.: La creación del estanco del tabaco en España, Madrid, 2002. El estudio específico del estanco valenciano ha sido abordado recientemente por SOLBES FERRI, S.: «El estanco del tabaco y la administración provincial de la renta en el Reino de Valencia (siglos XVII y XVIII)», en GRUPO DE ESTUDIOS DEL TABACO (GRETA), La renta del tabaco en el siglo XVIII: consumos y valores regionales, Fundación Altadis, (en prensa). Agradezco al autor que me facilitara la consulta de este último trabajo. 


\section{I) LA AGUDIZACIÓN DE LAS DISPOSICIONES DE CARÁCTER REGALISTA COMO CONSECUENCIA DE LA RESISTENCIA INICIAL DEL CLERO A LA IMPOSICIÓN DEL ESTANCO REAL DEL TABACO.}

Como se ha indicado anteriormente, el estanco del tabaco comenzó a introducirse en el Reino de Valencia de forma muy limitada a mediados del siglo XVII, ya que adquirió el carácter de un arbitrio municipal que, en las localidades en que se adoptaba, implicaba exclusivamente el monopolio de la venta al por menor del producto, sin afectar a su cultivo, elaboración y tráfico. De ahí la contundencia con que la monarquía procedió a su imposición cuando logró controlar el territorio tras la victoria conseguida en la batalla de Almansa. Su administración se segregó del resto de las rentas reales, cuya dirección corría a cargo del superintendente general Juan Pérez de la Puente, encomendándose el 4 de febrero de 1708 a Rodrigo Cavallero. El 26 de febrero posterior éste emitía el que puede considerarse como el bando fundacional del estanco real del tabaco en el territorio valenciano. Bajo la amenaza de duras penas, que llegaba a la de muerte en el caso de los plebeyos reincidentes, se prohibía su cultivo, dando un plazo de quince días para proceder al arranque de las plantaciones existentes y la destrucción de los molinos o utensilios utilizados en la elaboración del producto, e imponiendo el monopolio real en su abastecimiento y comercialización. Según la información que proporcionaba el propio Cavallero a finales del año 1709, la labor llevada a cabo hasta entonces había implicado la destrucción de 143 fábricas de tabaco y de numerosas plantaciones, generando la renta unos ingresos líquidos anuales cercanos al millón de reales de vellón, lo que suponía en torno al $20 \%$ del valor neto de las rentas reales del territorio, proporción que se mantuvo a grandes rasgos en los años posteriores ${ }^{6}$. Sin embargo, si en el citado informe aquel se vanagloriaba de la escasa resistencia que había provocado el proceso, la situación cambió cuando la contienda sucesoria estaba finalizando y culminó la escalada de la presión fiscal que ésta había comportado. En el caso valenciano, en concreto, el tránsito entre las contribuciones extraordinarias de guerra y la introducción del nuevo impuesto del equivalente dio lugar a que en 16 meses se pretendiese recaudar una suma total de 25,5 millones de reales de vellón, lo que triplicaba en exceso el cupo anual en que acabó fijándose el equivalente a partir de 1718. De ahí que, a pesar de que se recurrió a la colaboración del ejército para ejecutar el proceso, el descontento

6 Kamen, H.: La guerra de Sucesión en España. 1700-1715, Barcelona, 1974, pp. 349 y 353. Una copia impresa del bando de 26 de febrero de 1708 se halla en B.C.C.Ch.V. Sig. GM-538. N ${ }^{\circ}$ 33. Sobre el origen del estanco del tabaco en el Reino de Valencia durante el siglo XVII, ver SOLBES FERrI, S.: Op. Cit. Su contextualización en el conjunto de la fiscalidad de los territorios de la Corona de Aragón puede verse en BERNABÉ GIL, D.: «La fiscalidad en los territorios peninsulares de la Corona de Aragón durante la época de los Austrias», en ForTEA, J.I. y Cremades, C.M., Política y hacienda en el Antiguo Régimen. II Reunión Científica de la Asociación Española de Historia Moderna, Murcia, 1993, pp. 15-31. 
de la población se manifestase en la aparición de conatos de motines antifiscales, el más grave de los cuales tuvo lugar en Peñíscola en junio de 1715, dando lugar a que la monarquía acabase perdonando el $40 \%$ del cupo en que había fijado el equivalente en dicho año ${ }^{7}$. Fue en este contexto en el que el clero valenciano, aprovechando también la campaña en defensa de la inmunidad eclesiástica que emprendió el obispo Belluga en contra del incremento del precio de la sal, no sólo se atrevió a disputarle a la monarquía esta regalía, sino que cuestionó gravemente el estanco real del tabaco.

El conflicto se suscitó al localizar el resguardo de la renta en 1714 a cuatro eclesiásticos que habían adquirido 19 libras de tabaco de un navío inglés que se había aproximado a la costa. Con el auxilio de un ministro de la curia arzobispal, con el fin de velar por la inmunidad del clero, aquellos procedieron a su confiscación, alegando que se había cometido un delito de contrabando, y lo depositaron en el estanco que la renta tenía habilitado en el Grao. Cuando al día siguiente el tribunal eclesiástico reclamó la entrega del género confiscado, el administrador del estanco de la ciudad de Valencia, Felipe de Paz, se opuso alegando que era el juez conservador de la renta del tabaco el competente para resolver las denuncias de contrabando como la que se había producido. La reacción inmediata del Vicario General del Arzobispado de Valencia fue despachar un monitorio a Felipe de Paz amenazándole con la pena de excomunión si no procedía a la entrega del tabaco confiscado a la jurisdicción eclesiástica en el plazo de 24 horas. Éste solicitó inmediatamente el amparo de la Chancillería valenciana, la cual, aceptando su argumentación, instó a la Curia arzobispal a que revocase la decisión adoptada y se atuviese al sistema previsto para resolver los conflictos de competencias si consideraba que su jurisdicción había sido lesionada. Al no haber sido afectado por el decreto de abolición de los fueros, el método de resolución de los problemas de este tipo se basaba en la concordia firmada en 1372 entre la esposa de Pedro IV de Aragón y el cardenal Beltrán de Comenges, nuncio apostólico del papa Gregorio XI. Inicialmente el acuerdo favorecía a la jurisdicción eclesiástica, ya que con anterioridad los conflictos eran resueltos directamente por la jurisdicción real mediante la citación de los eclesiásticos afectados al «banco regio». En la concordia se establecía, en cambio, que los tribunales afectados por el conflicto debían proceder a la designa-

7 Sobre la acumulación de cargas fiscales que se produjo en el caso valenciano al final de la contienda sucesoria, ver FRANCH BENAVENT, R.: «La nueva fiscalidad implantada en los territorios de la Corona de Aragón tras la abolición del régimen foral: una aproximación desde la perspectiva valenciana», en Norba. Revista de Historia, n 16 , Cáceres, 2003, pp. 527-531. La evolución posterior del impuesto del equivalente ha sido estudiada en ROMEU LLORACH, J.: El sistema fiscal valenciano (1715-1823), Vinarós, 1981. Más recientemente en GARCía Trobat, P.: El equivalente de alcabalas, un nuevo impuesto en el Reino de Valencia durante el siglo XVIII, Valencia, 1999. Sobre el motín de Peñíscola, ver GIMÉNEZ, E.: «Oposición fiscal y reivindicaciones políticas. La revuelta de Peñíscola de 1715", en Gobernar con una misma ley. Sobre la nueva planta borbónica en Valencia, Alicante, 1999, pp. 111-123. 
ción de un árbitro, estipulando un plazo de tres meses para la resolución del problema. En caso contrario, los árbitros debían elegir a un tercero que decidiría definitivamente la competencia en el plazo máximo de un mes. Sin embargo, en el siglo XVI la monarquía consiguió controlar el sistema acortando a cinco días el primero de los plazos aludidos y convirtiendo al Canciller del Reino, designado por el monarca entre los miembros del alto clero que fuesen doctores en derecho, en el verdadero juez supremo de competencias del territorio. Como sus decisiones debían contar, además, con el asesoramiento de los miembros de la Audiencia, se había conseguido desnaturalizar completamente el sistema y afianzar su control por parte de la jurisdicción real ${ }^{8}$. Sin embargo, no se disponía de una garantía absoluta de que su funcionamiento se ajustase a las directrices de la monarquía, sobre todo en una etapa en que la tensión entre el poder real y el eclesiástico se había intensificado como consecuencia de la ruptura de relaciones con Roma en 1709 y la agudización de la polémica regalista. Así se pudo comprobar en este caso cuando el Canciller, desoyendo el parecer expresado por los miembros del tribunal de la Chancillería de Valencia, emitió sentencia el 30 de octubre de 1715 resolviendo el conflicto en favor de la jurisdicción eclesiástica.

Esta decisión vulneraba una de las competencias básicas que la monarquía consideraba inherente a su soberanía y amenazaba la importante fuente de recursos que la Real Hacienda había logrado imponer recientemente en el territorio. El Secretario de Hacienda ya le había trasmitido al Vicario General del Arzobispado de Valencia el malestar que su actitud estaba generando en la corte, no sólo por la protección que dispensaba a los abusos que cometían los eclesiásticos, sino también por el escándalo que provocaba esta circunstancia entre la población y la inducción al fraude que se derivaba de todo ello. De ahí la dureza de la advertencia que se le realizaba al comunicarle que, si no rectificaba su posición, «...pasaría Su Majestad a usar de los medios propios de su Real Soberanía y Potestad económica...». Sin embargo, el Vicario General, acogiéndose a lo que consideraba «...una sentencia irretractable, quales son las del Real Canceller...», decidió pasar a la ofensiva y comunicar sus argumentos a la sociedad mediante la publicación de las alegaciones jurídicas sobre las que se sustentaba su posición?. El escrito defendía dos principios básicos: la vigencia

8 El análisis de esta evolución puede verse en CANET APARISI, T.: La Audiencia valenciana en la época foral moderna, Valencia, 1986, pp. 142-148. Los conflictos de competencias suscitados en el siglo XVII por la represión del bandolerismo y las actividades delictivas protagonizadas por los eclesiásticos valencianos han sido estudiados por CALLADO EsTELA, E.: Inmunidad eclesiástica y delincuencia en el siglo XVII. Los arzobispos de Valencia y la pacificación del reino (1612-1699), Valencia, 2003. Sobre la jurisdicción eclesiástica, ver PÉREZ-PRENDES, J.M.: «El Tribunal eclesiástico (Sobre el aforamiento y la estructura de la Curia diocesana de justicia)», en MARTínEZ RUIZ, E. y PI CORRALES, M. de P. (coords.), Instituciones de la España moderna. I. Las jurisdicciones, Madrid, 1996, pp. 142-169.

9 El impreso, firmado por el Vicario General Jacinto Ortí, se titula: Alegación jurídica por la jurisdicción eclesiástica del Arzobispado de Valencia. Justicia de la sentencia dada por el Real Canceller en 30 
de la concordia suscrita en el siglo XIV para resolver los conflictos de competencia; y el ataque a la inmunidad eclesiástica que implicaba la imposición del estanco del tabaco. Sobre el primer aspecto, aparte de recordarse que la concordia aludida no había sido afectada por el decreto de abolición de los fueros, se subrayaba la imposibilidad del monarca de vulnerar el acuerdo alcanzado recurriendo a principios de carácter contractualista que resultaban muy peligrosos para la monarquía, ya que constituían la esencia del sistema político recientemente derogado. Aunque esta tesis se defendía más abiertamente en la polémica que se estaba sosteniendo paralelamente sobre el incremento de los precios de la sal, ya que se consideraba que el acuerdo suscrito por el monarca al respecto con el estamento eclesiástico había tenido lugar en el seno de las Cortes forales, el punto fundamental de partida era sustancialmente idéntico. En este caso se recalcaba concretamente que «...un contrato solemne estipulado entre el Príncipe y la Iglesia es irrevocable, y no puede, sin grave injuria de ésta, apartarse el Príncipe de su observancia...». La obligación de respetar lo estipulado en los contratos se sustentaba en los principios del derecho natural y de gentes. Si éstos amparaban incluso cualquier acuerdo contraído con los súbditos, con mayor motivo resultaba avalado un contrato tan solemne como el suscrito con la Iglesia sobre una materia tan trascendental como la relativa a la jurisdicción e inmunidad eclesiástica. Hallándose, por tanto, vigente la concordia firmada en el siglo XIV y habiendo resuelto la causa la instancia superior prevista en ella, es decir, el canciller, la monarquía no podía pretender que la jurisdicción eclesiástica renunciase a ejercer su competencia sobre la materia. No se consideraba válido el argumento de que la concordia no resultaba de aplicación para resolver los conflictos que afectaban a lo que se denominaba como «regalías notorias» de la Corona; entre otras cosas porque en el privilegio de nombramiento como canciller del Doctor Antonio Ferrer en 1678 se le facultaba expresamente para abordar dicha problemática.

Pero, junto a la validez de la concordia de contenciones, el aspecto más trascendental de las alegaciones de Jacinto Ortí era el cuestionamiento tanto de la consideración del tabaco como una regalía de la Corona como de la capacidad de ésta para imponer el estanco a los eclesiásticos. Aquella tesis se planteaba claramente en los siguientes términos: «...A más que el tabaco no es regalía; y sólo puede llamarse tal por estar estancado, que es lo mismo que decir que es regalía la facultad de estancar; y de este mismo modo podían llamarse regalías todas las cosas del mundo estancadas una vez por el príncipe...». Con mayor propiedad se podía aplicar dicha denominación a la sal, ya que todas las salinas del Reino habían sido incorporadas a la Corona. En todo caso, más que

de octubre de 1715 en la causa de contención suscitada por la jurisdicción real y D. Felipe de Paz, administrador o estanquero del tabaco. Sobre el monitorio o exorto despachado por el ordinario eclesiástico de dicha ciudad a dicho D. Felipe. Y observancia de lo declarado en dicha sentencia en lo venidero. B.C.C.Ch.V. Sig. 124-6/9. Nº 1 . 
negar a la monarquía la facultad de crear estancos, lo que realmente se discutía era el hecho de que éstos, generados por una ley secular, pudiesen afectar a los eclesiásticos. La razón básica que avalaba esta afirmación era la pretendida incapacidad del príncipe para legislar sobre cuestiones que afectasen a la inmunidad del clero. Se expresaba de esta forma la sutil equiparación que el estamento solía realizar entre sus miembros y los «no súbditos», en el sentido de que aquellos estaban tutelados por la jerarquía eclesiástica y protegidos por las disposiciones emanadas por la curia pontificia, entre las que jugaba un papel esencial la bula de la Cena. Al estar exentos, por tanto, de la legislación emitida por el príncipe secular, los eclesiásticos tenían libertad para adquirir los géneros que éste hubiese estancado donde les resultase más conveniente, sobre todo si lo hacían para satisfacer su consumo. Este derecho se reforzaba por la imposibilidad de aquel de percibir tributos que gravasen los bienes del clero sin el consentimiento de la jerarquía eclesiástica. De ahí que, sobre todo en el caso de los géneros estancados, sólo se les podía exigir el abono del precio «natural» del producto, con «alguna moderada ganancia». Si en el caso de la sal ya se había esgrimido este argumento, aún reconociendo que se trataba de una regalía de la Corona en su condición de propietaria de las salinas del Reino, con mucha mayor contundencia se repitió en el caso del tabaco: «...pues el tabaco que hoy en el estanco se les da por 10 reales, antes que se estancase se les vendía a 6 lo más caro; y aún pueden tenerle de balde cogiéndole en los huertos de sus casas...». Pero, además, en la medida en que la inmunidad no solamente protegía a las personas sino también a los bienes de los eclesiásticos, la jurisdicción real tampoco se consideraba competente para proceder a su confiscación, aún en el caso de que se sospechase que se estaba cometiendo fraude o contrabando. Siendo la jerarquía eclesiástica la que autorizaba o no la exigencia de contribuciones que afectaban al clero, correspondía también a su jurisdicción resolver cualquier conflicto que se suscitase sobre la materia. En caso contrario, «...sería obligar con coacción al eclesiástico a la observancia de la ley secular...», circunstancia no permitida por la legislación canónica, que hacía «...incapaz al secular de jurisdicción coactiva respecto del eclesiástico...». Por tanto, como puede apreciarse del tenor de los argumentos esgrimidos, las alegaciones elaboradas por el Vicario General de la diócesis valenciana cuestionaban seriamente tanto la soberanía real como la capacidad recaudatoria de la Real Hacienda. La amplitud que se otorgaba al concepto de inmunidad eclesiástica implicaba la imposibilidad de controlar las actividades llevadas a cabo por un colectivo tan numeroso e influyente que su aceptación hubiese comportado, no sólo una drástica reducción de los ingresos obtenidos, sino también la vía para la generalización de todo tipo de actividades fraudulentas, arruinando los esfuerzos realizados para afianzar las regalías de la Corona.

La respuesta de la monarquía se correspondió con la gravedad de la amenaza planteada, reforzando su autoridad mediante la emisión de una serie de disposiciones de carácter regalista que limitaban seriamente los privilegios de la Iglesia valenciana. En realidad, la propia legislación foral ya proporcionaba 
bastantes mecanismos para ello, siendo precisamente la existencia de medidas restrictivas de la inmunidad y jurisdicción eclesiástica uno de los motivos fundamentales que impulsaron a Felipe $\mathrm{V}$ respetar dicha normativa en el decreto de abolición de los fueros. Bastaba, pues, con ratificar su vigencia, añadiendo a las facultades que conferían a la Corona las generadas por el nuevo derecho de conquista adquirido con su victoria en la Guerra de Sucesión, para acabar con la interpretación favorable a sus intereses que el clero valenciano realizaba de la excepción realizada en el decreto abolicionista. Este fue el objetivo que se otorgó al decreto de 21 de diciembre de 1715 , recogido posteriormente en la Real Cédula de 17 de abril de 1716, que se convirtió en la disposición fundamental utilizada como referencia para la regulación de dichos aspectos en el resto de la centuria ${ }^{10}$. Su emisión pretendía aclarar el sentido de la Real Cédula de 7 de Septiembre de 1707 , sobre todo en lo relativo a las facultades que se derivaban de la inmunidad eclesiástica, «...que se pretenden extender a lo que no contienen, queriéndolas dar inteligencia que no fue de mi Real ánimo...». Con tal finalidad, se precisaba que la inmunidad local del clero no debía extenderse «...a más Iglesias que una en cada pueblo...», lo cual no hacía más que ratificar, aunque sin fundamentarla jurídicamente, una limitación que se hallaba vigente prácticamente desde la propia fundación del Reino de Valencia. Las ventajas que confería al poder real se comprenden en mayor medida teniendo en cuenta la modesta reducción del derecho de asilo que se consiguió para el resto del territorio español en el concordato de 1737 . Es más, la situación valenciana constituyó el modelo de referencia en las negociaciones mantenidas por José Moñino con la Santa Sede que condujeron a la emisión del Breve sobre reducción del derecho de asilo en España e Indias que otorgó Clemente XIV el 12 de septiembre de 1772. En el capítulo 12 del mismo se disponía, concretamente, que:

«...el número de los refugios y asilos, así como se halla muy minorado en el Reyno de Valencia desde tiempos muy antiguos por uso y general costumbre (quizás aprobada por privilegio y autoridad apostólica), así también en todas las ciudades y lugares de los Reynos de España y de las Indias se reduzca a una o dos, a lo más, en cada ciudad o pueblo, atendida proporcionalmente la amplitud de ellas o de ellos; de suerte que se tengan por refugio y asilo los que fueren propuestos y señalados por el Ordinario eclesiástico en cada ciudad o lugar...»11

10 La Real Cédula de 17 de abril de 1716 fue trascrita por Blas Jover en las páginas 29 y 30 del impreso que publicó en 1731 con el título: Defensa por la Jurisdicción Real y Renta del Tabaco del Reyno de Valencia; en las controversias suscitadas con la Real Audiencia del mismo y la Curia episcopal de Oribuela. Biblioteca Universitaria de Valencia (B.U.V.). Sig. Varios, 97/11.

11 El Breve papal de 1772 se halla trascrito en ESPUNY TOMÁs, M.J. y SARRIÓN GUALDA, J.: «El derecho de asilo en Cataluña durante el siglo XVIII», en Església i societat a la Catalunya del segle XVIII, Cervera, 1990, Vol. II, pp. 137-182. En su cumplimiento, impulsado por la Real Cédula de 14 de enero de 1773, el obispo de Barcelona, José Climent, redujo a dos las iglesias que conferían derecho de asilo en la capital y a una en el resto de las localidades. El análisis de la misma 
Con respecto a los límites de la inmunidad personal del clero, en la Real Cédula de 17 de abril de 1716 se precisaba que, además de los derechos y las regalías que pertenecían a la Corona por fueros, costumbres y concesiones pontificias, debían contemplarse también «...los que por derecho de conquista me pertenecen y pueden pertenecer...». Es decir, era aquí donde el poder real se reforzaba en mayor medida al aplicarse también al clero el principio básico que se esgrimió para justificar la abolición de la legalidad foral. En todo caso, se disponía que en los conflictos que afectasen a las regalías reales, entre las que se citaba expresamente el estanco del tabaco, «...no se pueda formar ni admitir contención alguna, y que se proceda por caso notorio, usando de el medio de la citación a el Banco Regio, extrañeza y temporalidades...». Afianzado, de esta forma, el principio básico de que aquellas constituían un derecho incuestionable que se derivaba de la soberanía real, se podía proceder con mayor facilidad a la aplicación del método expeditivo existente con anterioridad a la concordia del siglo XIV para resolver los conflictos relativos a lo que la propia Corona considerase particularmente como una «regalía notoria».

No obstante, la contundencia de esta disposición no disuadió al clero valenciano de continuar esgrimiendo los derechos que se derivaban de su inmunidad personal. Así lo constataba el Consejo de Castilla en la consulta que elaboró el 12 de abril de 1717, en la que recalcaba que los miembros del citado estamento seguían realizando una interpretación abusiva de dicha facultad, hasta el punto de considerar «...por lícito, no sólo usar de la libertad de comprar tabacos, sino es de defraudar esta renta, haziendo granjería como los seculares más relajados...». Se destacaba, así mismo, la responsabilidad que correspondía al

problemática en el obispado de Calahorra y la Calzada puede verse en ANGULO MORALES, A.: «La limitación del derecho de asilo en sagrado. Medidas contra el contrabando en la España del siglo XVIII», en Cuadernos de Investigación Histórica, $\mathrm{n}^{\circ}$ 20, Madrid, 2003, pp. 267-298. Anteriormente, en los artículos 2, 3 y 4 del concordato de 1737 sólo se limitó el derecho de asilo en las «iglesias frías» (es decir, fuera del recinto sagrado del edificio) y en las ermitas o iglesias rurales en las que no se custodiase el «Santísimo Sacramento». Una trascripción del mismo puede verse en el Apéndice II de García Villoslada, R. (dir.): Op. Cit., pp. 797-802. La limitación del derecho de asilo en el caso valenciano ya se dispuso en los fueros concedidos por Jaime I, al otorgarse «... a la esglesia de Sancta María e de Sant Vicent e a la huna major esglesia de cascun lloch del Regne de Valencia...». Fori Regni Valentiae. Libro I, rúbrica IX, fuero IV. También la recoge la obra del mejor tratadista valenciano de la época foral, MATHEU y SANZ, L.: Tractatus de Regimine urbis et Regni Valentiae sive selectarum interpretationum ad principaliores foros eiusdem, Valencia, 1654-1656. Capítulo VII, párrafo I, números 164 y 165. Agradezco a los Drs. Rafael Benítez Sánchez-Blanco y Teresa Canet Aparisi que me facilitasen la localización de estas referencias. Las Cortes valencianas de la época foral moderna fueron precisando dicho derecho, aunque manteniendo esencialmente la limitación establecida en el fuero IV. Así se puede comprobar, por ejemplo, en las Cortes de 1564, cuando los estamentos solicitaron que la citada inmunidad fuese respetada también por la Inquisición, salvo en el caso de los delitos de herejía. Salvador Esteban, E.: Cortes Valencianas del reinado de Felipe II, Valencia, 1974. Ver el capítulo XIII de las citadas Cortes, p. 12. Aquella limitación consta también en la concordia firmada en 1604 por el Patriarca San Juan de Ribera y Felipe III, según indica Callado Estela, E.: Op. Cit., pp. 18-19. 
Vicario General del Arzobispado valenciano en el mantenimiento de estos desafíos, ya que no sólo toleraba los citados abusos, sino que continuaba entorpeciendo su represión por parte de la jurisdicción real esgrimiendo su competencia en la materia y suscitando de forma reiterada conflictos jurisdiccionales. De ahí que se considerase ya imprescindible la adopción de una medida ejemplarizante que pusiese de manifiesto la determinación real de no seguir tolerando desafíos de esta naturaleza. El dictamen del fiscal ya se inclinó por la conveniencia de proceder a la expulsión de los eclesiásticos más implicados en el problema. El consejo pareció optar por una respuesta más moderada, proponiendo que se ordenase comparecer en la corte a tres de ellos; se le advirtiese de nuevo al Vicario General de la diócesis valenciana que carecía de jurisdicción sobre la materia; y se le recordase a la Audiencia del territorio que no debía admitir en el futuro ningún conflicto de jurisdicción al respecto, según se había dispuesto en las órdenes anteriores. De las tres medidas aludidas sólo se ha podido constatar el cumplimiento de la última de ellas, ya que la Real Provisión emitida en dicho sentido el 19 de mayo de 1717 fue trascrita por Blas Jover, como otra de las disposiciones fundamentales que avalaban la competencia de la jurisdicción real en las causas generadas por la renta del tabaco, en el impreso que publicó al respecto en $1731^{12}$. Lo que parece evidente, en todo caso, es que la obstinación del clero valenciano en el cuestionamiento de las regalías de la Corona alegando la defensa de su inmunidad estaba colmando la paciencia de la monarquía. De ahí la respuesta fulminante que se produjo ante la excomunión del intendente Rodrigo Cavallero por parte del Vicario General como consecuencia de un nuevo incidente relacionado, en esta ocasión, con la adquisición fraudulenta de sal por parte de la cartuja de Ara Christi. El 4 de julio de 1717 Felipe V ordenaba al Capitán General que procediese a la expulsión no sólo del citado Vicario sino también de los cuatro canónigos que, según la opinión del Consejo, se habían significado más como «...enemigos manifiestos de las justas regalías del Rey...»13. Con la adopción de esta medida se puede considerar que se ponía término a la etapa en la que el clero valenciano se opuso con mayor firmeza a la erosión de su inmunidad que comportó el reforzamiento del poder real como consecuencia de la Guerra de Sucesión. El resultado de su resistencia no podía ser más decepcionante, pues, al negarse el cabildo a sustituir durante más de dos años al Vicario General expulsado y permanecer el arzobispo titular, Antonio Folch de Cardona, exiliado en Viena hasta su muerte en 1724, la Iglesia valenciana acabó estando prácticamente descabezada. La normalización de las relaciones con Roma por parte de la corte española que implicó la firma del concordato de 1717 y, sobre todo, la designación como arzobispo de Valencia, tras el falleci-

12 B.U.V. Sig. Varios. 97/11, pp. 31-32. La consulta del Consejo de Castilla de 12 de abril de 1717 y el informe del fiscal pueden verse en Archivo Histórico Nacional (A.H.N.). Consejos. Leg. 6812. Exp. No 19 y 39.

13 El análisis de este conflicto puede verse en FrANCH, R.: «El cambio de naturaleza de las rentas...cit., pp. 280-281. 
miento de su antecesor, de un prelado muy vinculado al poder real (Andrés de Orbe y Larreátegui, que llegó a ejercer simultáneamente el cargo de gobernador del Consejo de Castilla entre 1727 y 1733 y de Inquisidor General después), contribuyen a explicar la menor virulencia que adquirió la contestación de la autoridad real por parte del clero valenciano a partir de entonces.

\section{II) EL MANTENIMIENTO DE LA RESISTENCIA LARVADA AL ESTANCO DEL TA- BACO POR PARTE DEL CLERO VALENCIANO: SU MANIFESTACIÓN EN EL MOTÍN DE AYORA DE 1730.}

El apaciguamiento de la resistencia abierta presentada por el clero valenciano a la imposición del estanco del tabaco no logró impedir que los miembros de dicho estamento continuaran cuestionando la vulneración de su inmunidad personal que, desde su punto de vista, suponía la existencia del monopolio real. En concreto, seguían considerando que su finalidad era la percepción de un tributo por parte de la monarquía, por lo que, al hallarse exento el clero de las contribuciones que se hubiesen creado sin su expreso consentimiento, sus miembros no podían ser obligados a adquirir el tabaco al precio fijado oficialmente en los establecimientos autorizados para ello. Consecuentemente, se sentían legitimados para conseguir el producto, sobre todo si se destinaba para su consumo, a través del sistema que les resultase más favorable, incluyendo, no sólo su cultivo y transformación, sino también su adquisición por las vías existentes al margen de las legalmente establecidas. Todo parece indicar que esta mentalidad no era exclusiva del clero valenciano, sino que la compartía el conjunto de sus componentes en el territorio español. Sólo así resultan comprensibles los resultados de los autos de la renta del tabaco del Reino de Sevilla entre 1670 y 1730 que ha analizado J.M. Rodríguez Gordillo y en los que los eclesiásticos son, junto con los arrendadores y administradores de la renta, los principales defraudadores, con unas actividades que, según destaca el citado autor, "...alcanzan una asiduidad que llega a sorprender al estudiarlas...». Realmente, como apunta B. Yun Casalilla, el fraude hay que insertarlo en las categorías mentales de la época, ya que lo que la administración fiscal presentaba como tal podía ser simplemente para los interesados una reacción natural contra la vulneración de los privilegios de que gozaban ${ }^{14}$. Evidentemente, esta legitimación de actividades que, al fin y al cabo, eran consideradas ilegales constituía la puerta abierta para la realización de todo tipo de abusos, incluyendo la intervención directa en el tráfico de contrabando o la imbricación y

14 Yun Casalilla, B.: «Corrupción, fraude, eficacia hacendística y economía en el siglo XVII», en El fraude fiscal en la Historia de España. Monografía $\mathrm{N}^{\circ} 1$ de Hacienda Pública Española, Madrid, 1994, p. 55. En este mismo volumen se halla el estudio aludido de RODRíGUEZ GORDILLO, J.M.: «El fraude en el estanco del tabaco (siglos XVII-XVIII)», Ibidem, p. 71. 
protección dispensada a las redes que lo efectuaban. Si las vinculaciones de este último tipo se han podido comprobar en lo que se ha considerado como el único motín protagonizado por contrabandistas en la España dieciochesca, el que tuvo lugar en Ceclavín en 1755'15, en el caso valenciano se produjo con 25 años de antelación una manifestación de la misma naturaleza que fue inducida directamente por los eclesiásticos.

El escenario del conflicto fue la localidad de Ayora, ubicada en el interior de la actual provincia de Valencia y situada en el límite con Castilla. Esta circunstancia, junto con su naturaleza mayoritariamente montañosa, favoreció la proliferación del contrabando entre ambos territorios durante el periodo foral. La eliminación de las aduanas internas como consecuencia de la Guerra de Sucesión redujo de forma considerable las oportunidades que existían para ello, pero no las anuló completamente, puesto que los antiguos límites separaron a partir de entonces las administraciones fiscales de ámbito territorial. En estas condiciones, la existencia de distintos tipos de gravámenes o, sobre todo, diversos niveles de precios de los productos estancados, podía estimular un tráfico ilegal que resultase bastante remunerativo. Así ocurría particularmente en el caso del tabaco, puesto que, hasta la unificación de precios de 1741, el producto se vendía con un recargo muy superior en el caso valenciano, situándose a principios de la década de 1730 en torno a los 23,4 reales de vellón la libra frente a los 17,2 que se exigían en Castilla ${ }^{16}$. A este factor se añadió la pertenencia de Ayora, en el ámbito de la administración eclesiástica, al obispado de Orihuela, cuyo prelado, José Flores Osorio, mantuvo una posición mucho más crítica hacia las regalías de la Corona que la que se impuso en Valencia a partir de mediados de la década de 1720 . Según se indicaba en el impreso publicado por Blas Jover en 1731, el propio obispado estaba manteniendo entonces un grave conflicto con los responsables de la renta del tabaco de Orihuela que había conducido a la excomunión del visitador de la renta, su teniente y tres miembros del resguardo. La causa se derivaba del apresamiento en la portería del convento de San Agustín de dicha ciudad de un tonsurado al que se acusaba de defraudador. La interpretación abusiva de la inmunidad eclesiástica que realizaba el obispado no podía ser, según Jover, más evidente, ya que el citado convento carecía de ella, al haberse reducido a una iglesia de cada localidad en la Real Cédula de 17 de abril de 1716, y al disponer el encausado de la simple condición de tonsurado, excluida de los beneficios de aquel privilegio desde mediados del siglo XVI. De ahí que atribuyese el problema al nepotismo imperante en el citado obispado, subrayando que el acusado, Manuel Vigo, era primo hermano del canónigo José Juan Vigo y del abogado de cámara del obispo

15 Melón JiméneZ, M.A.: Hacienda, comercio y contrabando en la frontera de Portugal (siglos XVXVIII), Cáceres, 1999, pp. 193-230.

16 Solbes FerRi, S.: Op. Cit. El contexto socioeconómico de la localidad puede verse en Palop, J.M. y BENíTEZ, R.: «La distribución social de la renta en Ayora a fines del siglo XVIII», en Congreso de historia rural. Siglos XV al XIX, Madrid, 1984, pp. 459-469. 
Francisco Crespo, además de «...estrecho confidente y amigo del Vicario General...». Recalcaba, además, la gravedad que tenía el conflicto al hallarse excomulgado buena parte del resguardo de la renta en una zona que, al ser «...la puerta del Reino de Murcia y puerto de Cartagena para las entradas en éste, se halla abierta para todo género de fraudes... ${ }^{17}$. No cabe duda que este nuevo cuestionamiento del estanco del tabaco por parte de la jerarquía eclesiástica de su diócesis en defensa de la interpretación tradicional del concepto de inmunidad, a pesar de las reiteradas órdenes que habían limitado sus implicaciones, debió inducir al clero de Ayora a llevar a cabo un desafío de la autoridad real tan grave como el que realizó en 1730 .

El detonante del conflicto fue la pretensión de la ronda del tabaco de proceder el día 26 de agosto de 1730 al registro de la habitación del presbítero Joseph Ródenes, suponiendo que existía en ella tabaco adquirido fraudulentamente. Se trataba de una operación delicada, no solamente porque éste era hijo del alcalde de la localidad, Pablo Ródenes, sino también porque, al acusarse a un eclesiástico, se tuvo que recurrir, para que supervisase el proceso, al auxilio del vicario de la misma, Francisco Teruel, «...pariente en grado conocido...» del citado presbítero. De ahí la tensión existente y la «acalorada pasión», en palabras del Consejo de Castilla, con la que procedió la ronda, sobre todo cuando el vicario trató de arrogarse en exclusiva la facultad de realizar el registro sin intervención de los responsables de la misma. En pleno forcejeo, el vicario requirió al alcalde, bajo pena de 25 libras y de excomunión, que le proporcionase 50 hombres armados para contener a los miembros de la ronda. E inmediatamente, las campanas de las iglesias de la localidad tocaron a rebato, "...cuyo delito es capital en este Reyno después de la conquista...», según destacaba el Capitán General en el informe que emitió al respecto, y la población se amotinó armada con «...escopetas, palos y otras armas...». Ante la presión existente, los miembros de la ronda se retiraron de la localidad sin llevar a cabo el registro que pretendían, lo que implicaba una intensa humillación del sistema de control que había establecido la administración hacendística. Pero, además de este desafío, el vicario de Ayora aprovechó la ocasión para convocar una asamblea del clero de la localidad y adoptar un acuerdo que recogía realmente el verdadero sentir de los miembros del colectivo. Según lo trascribía Blas Jover, su tenor era el siguiente: «...Que todos los eclesiásticos de aquella villa se pudiesen libremente proveer del tabaco que necesitasen en los Reales Estancos de Castilla o de cualesquiera otras provincias sujetas a Su Majestad donde lo hallasen con mayor conveniencia...». A pesar de que la posibilidad se restringía al sistema legal de venta existente en el territorio español, el acuerdo vulneraba la prohibición vigente del tránsito del tabaco entre las diversas circunscripciones administrativas sin la licencia expresa de los responsables de éstas. De llevarse a cabo, destacaba Jover, la renta del tabaco del Reino de Valencia sufriría

17 B.U.V. Sig. Varios $97 / 11$, pp. 74-75. 
un grave perjuicio, puesto que en todos los territorios circundantes «...los arrendadores tienen los tabacos a precios más cómodos...». De hecho, en la citada asamblea se había encomendado a un eclesiástico que pasase al lugar que resultase más ventajoso para adquirir 60 libras de tabaco con las que abastecer a los entre 28 y 30 miembros del clero que existían en la localidad. No cabe duda, pues, que el clero se estaba escudando, de nuevo, en su inmunidad para aprovecharse de las contradicciones existentes en el sistema administrativo creado por la renta del tabaco y tratar de reducir al máximo la contribución que abonaba por el consumo del citado producto.

El Capitán General de Valencia, el Príncipe de Campoflorido, trató de castigar severamente el desorden que se había producido en Ayora. Además de los graves delitos cometidos en el curso del desencadenamiento del motín, consideraba que no se debía tolerar en el territorio ningún atentado contra las regalías reales, tanto por su reciente implantación «por derecho de conquista» como por el rechazo que provocaban entre la población y el apoyo que prestaban los eclesiásticos a las actividades fraudulentas. De ahí que, con el fin de identificar a los responsables, encargó al alcalde mayor de Alzira, Pedro Solís y Mesía, que se trasladase a Ayora y procediese a la instrucción de la causa que se debía abrir al respecto. Sin embargo, el proceso complicó aún más el problema al dar lugar a un nuevo enfrentamiento entre la jurisdicción real y la eclesiástica que alcanzó un elevado grado de crispación. En el curso de la investigación que estaba llevando a cabo el juez comisionado, Pedro Solís, el vicario de Ayora le exigió, bajo amenaza de excomunión, que le permitiese interrogar a los sospechosos, todos ellos laicos, que había ordenado encarcelar. Su demanda incumplía los requisitos formales que regían las relaciones entre ambas jurisdicciones, puesto que, según destacaba Jover, se hallaba establecido que «...primero se pida; que si se le negare, amoneste; que si todavía se le resistiere, aperciba; y, por último término, mande...». A pesar de ello, Solís le otorgó al vicario permiso para acceder a la cárcel. Pero lo más grave fue que éste, tras interrogar a varios presos, consideró que la causa abierta afectaba a la inmunidad eclesiástica al constatar que Solís les había preguntado sobre la actitud mantenida por el clero durante el motín. En consecuencia, el 13 de octubre de 1730 requirió, tanto a éste como a su escribano, que sobreseyesen la causa, entregasen los autos a la jurisdicción eclesiástica y compareciesen ante él en el término de tres días para asistir al procedimiento de su excomunión, que llevó a cabo efectivamente en su ausencia. Lógicamente, tanto los afectados como el recaudador de la renta del tabaco solicitaron el amparo de la Audiencia, la cual, ateniéndose a la condición de «regalía notoria» que se había otorgado al estanco en las órdenes emitidas en 1716 y 1717, requirió al vicario de Ayora que revocase las medidas adoptadas y pasase a informar al «Banco Regio» de los fundamentos con los que había procedido. Al mismo tiempo, el Capitán General comunicó al obispo de Orihuela el malestar que la actuación del vicario estaba generando, solicitándole que procediese a su amonestación y le exigiese el abandono del procedimiento emprendido. Sin embargo, el prelado, alegando la necesidad de cono- 
cer previamente la situación, comisionó al vicario de la vecina localidad de Caudete para que procediese a comprobar si era cierto que Solís había orientado la instrucción del proceso en la participación del clero en el motín. Como éste corroboró dicha circunstancia, se inició una escalada de amonestaciones mutuas entre la Audiencia y el Vicario General del obispado de Orihuela que culminó con la notificación del monitorio de excomunión de los miembros de aquel tribunal, el cual se comunicó «...al señor Regente de esta Audiencia la mañana del día 29 de diciembre, siendo uno de los feriados de Pascua, en la Santa Metropolitana Iglesia a tiempo que se hallava oyendo misa en ella y expuesto el Santísimo, contra el decoro y urbanidad que se debe a lo sagrado del lugar y al carácter de este ministro...». Realmente, la complejidad del problema había dividido a los propios miembros de la Audiencia, ya que en la reunión del Real Acuerdo que convocó el Capitán General el día 4 de diciembre anterior la mayoría de ellos se mostraron partidarios de mantener el procedimiento legal que se había emprendido para resolver el problema. En cambio, su presidente, el Príncipe de Campoflorido, consideraba imprescindible la adopción de una resolución expeditiva que lo eliminase, por lo que, a pesar de la división de opiniones indicada, el 11 de diciembre posterior informaba al consejo que «...si estos hechos quedan tolerados en un Reyno donde se empieza a establecer la Renta del tabaco y las demás regalías de Su Majestad, será irreparable su daño en lo sucesivo, y dificultoso de mantener la quietud pública si no se escarmienta a alguno de los eclesiásticos que tan libremente la perturban...»18.

La trascendencia que había adquirido el conflicto impulsó a intervenir en la polémica a uno de los funcionarios que consiguió desarrollar con posterioridad una carrera política especialmente brillante: Blas Jover Alcázar. Estaba ejerciendo aún entonces el cargo de alcalde mayor de Valencia, aunque se había vinculado intensamente con el intendente Francisco Salvador de Pineda, quien le nombró como asesor en 1730. Fue posteriormente cuando experimentó un ascenso fulgurante, al ocupar en 1733 el cargo de alcalde del crimen de la Audiencia de Valencia y pasar en 1738 a la corte, donde fue nombrado fiscal de la Junta de Baldíos, miembro del Consejo de Hacienda desde 1740 y fiscal de la Cámara de Castilla desde 1744. En este último destino se encargó precisamente de gestionar los asuntos relacionados con el Real Patronato, es decir, las regalías de la corona en materia eclesiástica. La responsabilidad adquirida en el ejercicio de dicho cargo le convirtió, gracias al apoyo intelectual prestado por el ilustrado Gregorio Mayans, en una de las figuras más relevantes de la polémica que la monarquía sostuvo con la Santa Sede en defensa de sus atribuciones, sentando las bases de las concesiones obtenidas en el Concordato de 1753. Por tanto, el impreso que publicó en 1731 con el título «Defensa por la jurisdicción

18 A.H.N. Consejos. Leg. 6823. Exp. $\mathrm{N}^{\circ}$ 11. Tanto la narración de los acontecimientos que tuvieron lugar durante el motín como el conflicto jurisdiccional posterior se pueden ver en este expediente y en el impreso publicado por Blas Jover en 1731. B.U.V. Sig. Varios 97/11. 
real y renta del tabaco del Reyno de Valencia...»19 ${ }^{19}$ constituye un reflejo precoz de los argumentos de una de las personalidades más destacadas del regalismo español de la primera mitad de la centuria. Aparte de relatar críticamente la actuación del vicario de Ayora y de la jurisdicción eclesiástica en los acontecimientos descritos con anterioridad, el principio fundamental que sustentaba su argumentación era la capacidad del poder secular para emitir disposiciones que afectasen a todos sus súbditos, incluyendo a los miembros del clero. Se basaba para ello, sobre todo, en el tratado «De lege política» de Pedro González de Salcedo, cuestionando, en cambio, las tesis contrarias sustentadas por el padre Antonino Diana, en defensa de la inmunidad eclesiástica, y el tratado sobre el contrabando del clero elaborado por el napolitano Carlos Cala ${ }^{20}$. En concreto, estos últimos sostenían, según su interpretación, que la ley secular «...govierne, no mande; dirija, y no obligue forzosamente al eclesiástico; y, en su consecuencia, que éste no esté sugeto a las leyes prohibitivas y penales por defecto de potestad en el que las promulgó...». Frente a ello, avalaba la tesis aludida aportando la legislación emitida desde la Baja Edad Media, inicialmente sobre la saca de moneda y después sobre el contrabando, destacando en este sentido la Pragmática de 31 de enero de 1650, en la que se indicaba expresamente que no se admitiría ninguna exención o privilegio que limitase su cumplimiento. La jurisdicción real era competente, por tanto, para proceder al embargo de las mercancías ilícitas que se localizasen, remitiendo, no obstante, la causa con posterioridad a la jurisdicción eclesiástica para que impusiese la pena correspondiente si el infractor era un miembro del clero. Pero más que en el terreno práctico, donde, como puede apreciarse, la posición defendida era moderada al tener que ajustarse a la legalidad vigente, las tesis más importantes se sostenían en el ámbito de los principios. Subrayando que los eclesiásticos formaban parte de la «república» y equiparando ésta al cuerpo humano, cuya cabeza sería el príncipe, defendía con rotundidad que aquellos estaban obligados a obedecer las disposiciones del poder secular. Apelaba también a los principios del derecho natural para

19 B.U.V. Sig. Varios 97/11. Sobre las negociaciones del concordato de 1753 y el apoyo intelectual prestado por Gregorio Mayans a Blas Jover, ver MESTRE SANCHIS, A.: «La Iglesia y el estado. Los concordatos de 1737 y 1753», en JOver ZAMORA, J.M. (dir.), La época de los primeros Borbones. La nueva monarquía y su posición en Europa (1700-1759), tomo XXIX, volumen I de la Historia de España de Menéndez Pidal, Madrid, 1985, pp. 319-333. La biografía de Blas Jover puede verse en el estudio preliminar de MOLAS, P.: Gregorio Mayans y Siscar. Epistolario XI, Mayans y Jover, 1. Un magistrado regalista en el reinado de Felipe V, Valencia, 1991.

20 Las tres obras aludidas se hallan en la Biblioteca Nacional, y su referencia es la siguiente: GonZÁlez DE SALCEDO, P.: De lege politica, eiusque naturali executione, et obligatione, tam inter laicas, quam eclesiásticos, ratione boni communis, Madrid, 1642. Sig. 3/62311; DiANA, A., Resolutionum moralium pars quinta: in qua selectiores casus conscientiae sub variis tractatibus explicantur: additae in extremo operis declaraciones sacrum congregationum Rotae que romanae decisiones circa materiam immunitatis Ecclesiae, Madrid, 1640. Sig. 6/2866; la obra de Carlos Cala figura sin autor ni fecha de publicación con el título: De contrabannis Clericorum in rebus extrahi probibitis a Regno Neapolitano: Dissertatio iuridico-politica. Sig. 2/10188(2). 
recalcar que las leyes que dicta el príncipe no tenían un carácter arbitrario si lo que perseguían era el bien común de la «república», el cual era superior al interés particular. De ahí que, si bien admitía que los eclesiásticos estaban exentos de la jurisdicción real, consideraba que «...no podemos considerarles tales en quanto a que estén libres de la Potestad y Soberanía Real, viviendo a su arbitrio y obrando en daño y perjuicio del bien común...». Rebatiendo, de esta forma, la identificación que los tratadistas del clero solían realizar entre los eclesiásticos y los «no súbditos», Jover avalaba la legalidad del registro que la ronda del tabaco pretendió realizar al presbítero de Ayora y el atentado a la soberanía real que hizo el vicario de dicha localidad al impedirlo.

Junto con la afirmación de la soberanía real, el impreso de Blas Jover pretendía también justificar la legalidad del procedimiento seguido por la Audiencia valenciana frente a los «excesos» cometidos por la jurisdicción eclesiástica. La incorrección de ésta se había producido ya en el episodio inicial del conflicto, cuando el vicario de Ayora se extralimitó en sus funciones, amenazando con un castigo pecuniario al alcalde de la localidad y actuando de forma imperativa frente a la jurisdicción real. Precisaba, al respecto, que la jurisdicción eclesiástica sólo podía imponer penas canónicas a los laicos, debiendo, además, elevar de forma paulatina el tono de sus amonestaciones a los oficiales reales (primero exhortar, luego conminar o apercibir, y, sólo finalmente, mandar) cuando entraba en conflicto con ellos. Estos motivos, junto con la inducción al motín y el acuerdo ilegal adoptado por la asamblea local del clero, ya justificaban que la Audiencia hubiera procedido a la resolución del conflicto de forma expeditiva, citándole al «Banco Regio» y procediendo a la ocupación de sus temporalidades si no corregía su actitud. Como todos estos hechos tuvieron lugar, además, antes de que el alcalde mayor de Alzira iniciara la instrucción del proceso, que era el motivo alegado por el obispado de Orihuela para sostener el conflicto jurisdiccional, invalidaban también la actuación de éste, que debía haber amonestado al vicario en lugar de avalar sus irregularidades. Recordaba, además, que la Audiencia no podía admitir el recurso a la concordia de contenciones de 1372 que solicitaba el obispado porque la monarquía había declarado de forma reiterada (sobre todo en las órdenes de 1716 y 1717 citadas con anterioridad) que el estanco del tabaco era una «regalía notoria» cuya jurisdicción competía exclusivamente a los tribunales reales. Finalmente, avalaba la corrección de la investigación llevada a cabo por el juez comisionado, Pedro Solís, subrayando los límites de la inmunidad eclesiástica. Rechazaba de plano que su origen proviniese del derecho divino, como defendía Antonino Diana. Destacaba, en cambio, la diversidad de opiniones existente entre los que la atribuían exclusivamente a una concesión de la autoridad real y los que consideraban, en cambio, que procedía del derecho canónico. Esta última opinión es la que creía más probable, avalándola con la tesis sostenida por Francisco Suárez en el sentido de que su origen era de «derecho humano y Pontificio». En todo caso, consideraba que esta variedad de interpretaciones legitimaba a los príncipes a «...que pongan en ella la mano con toda seguridad...». La justificación que se podía 
alegar para ello era muy diversa, ya que, junto al privilegio otorgado por la Santa Sede o su consentimiento tácito o expreso, se contemplaba también la posesión inmemorial, el derecho natural de la propia defensa y el derecho de «...Patronato que goza en todas las iglesias de sus Reynos...», es decir, la principal reivindicación que se plantearía en las negociaciones del concordato de 1753. De todas formas, descendiendo de los principios teóricos al caso concreto sobre el que se estaba polemizando, Jover consideraba evidente que el juez comisionado no podía haber atentado contra la inmunidad eclesiástica cuando se limitó a efectuar un interrogatorio con el fin de dilucidar los posibles delitos cometidos en el desencadenamiento del motín, sin encausar a ningún eclesiástico. En conjunto, pues, la defensa de los límites tanto de la inmunidad como de la jurisdicción eclesiástica y la rotunda afirmación de la superioridad de la soberanía real frente al poder temporal de la Iglesia constituyen los principios fundamentales sobre los que se sustentaba el impreso publicado por Blas Jover en 1731. De ahí que su posición firmemente regalista, junto con el apoyo de la red clientelar en la que se insertaba y el soporte intelectual de Mayans, le permitiesen jugar posteriormente un papel tan trascendental en la polémica entablada por la monarquía con la Santa Sede sobre el Patronato real.

La publicación del impreso de Jover revela la vehemencia con la que los representantes de los dos poderes enfrentados sostuvieron sus posiciones y, consiguientemente, la intensa repercusión que adquirió el conflicto en la sociedad valenciana de la época. La dinámica que se había generado resultaba muy peligrosa, puesto que la acidez de los reproches que aquellos se realizaban corría el riesgo de debilitar y desprestigiar a las propias instituciones a las que pertenecían. Así se lo planteaba el Vicario General del arzobispado de Valencia en la carta que le dirigía a su superior, que se hallaba ejerciendo el cargo de gobernador del Consejo de Castilla, el 17 de enero de 1731. En ella le trasmitía la entrevista que había tenido con el Capitán General de Valencia, a quien le había solicitado que impidiese la difusión del citado impreso «...porque no dexaría el Señor Obispo u otro de responder a él, y bastantemente está este pueblo con expectación para ver el paradero de este negocio...». De ahí la delicada posición en la que se encontraba el citado arzobispo y la relativa ecuanimidad con la que trató de resolver el conflicto. La consulta que elaboró finalmente el Consejo el 18 de junio de 1731 es una buena muestra de ello, puesto que atribuía a ambas partes la responsabilidad del problema y, consiguientemente, realizaba una propuesta muy moderada ${ }^{21}$. Siguiendo la opinión expresada por el fiscal, se diferenciaba la existencia de dos procedimientos distintos. El primero de ellos comprendía desde el registro que pretendía hacer la ronda del tabaco hasta el acuerdo adoptado por la asamblea del clero de Ayora. Como en estos hechos se había vulnerado la «regalía» de la renta del tabaco, la jurisdicción real no podía admitir un conflicto de competencias, estando obligada a

21 A.H.N. Consejos. Leg. 6824. Exp. No 6. La carta del Vicario General aludida en el texto se halla en el expediente $\mathrm{n}^{\circ} 7$ del mismo legajo. 
requerir a la jurisdicción eclesiástica la revocación de sus procedimientos, con citación de comparecencia ante el «banco regio» en caso contrario. En cambio, el conflicto suscitado entre el alcalde mayor de Alzira, como juez comisionado, y los vicarios de Ayora y Caudete, éste último comisionado por el Vicario General del Obispado de Orihuela, en el que se dirimía el posible atentado a la inmunidad eclesiástica del interrogatorio realizado por el primero, debía resolverse recurriendo a la concordia de contenciones de 1372 . El Consejo consideraba que ninguna de las partes implicadas había diferenciado la existencia de ambos procedimientos, dando lugar a la confusión de ambos y, por tanto, a la adopción de resoluciones erróneas. En concreto, se censuraba sobre todo a la Audiencia que hubiese actuado en contra del vicario de Caudete, a pesar de que éste intervenía como comisionado del Vicario General del obispado, lo se debería haber resuelto recurriendo a la concordia de contenciones. A su vez, se reprochaba al citado Vicario General que, además de apoyar implícitamente los excesos cometidos por el vicario de Ayora, hubiese considerado lesionada la inmunidad eclesiástica con el simple interrogatorio de unos cuantos presos, cuando en el sumario instruido por el alcalde mayor de Alzira se podía comprobar que no se estaba procediendo contra ningún miembro del clero. Teniendo en cuenta la confusión con la que habían procedido ambas partes, se proponía actuar con benignidad, sin adoptar las resoluciones más severas a las que la monarquía podía recurrir en uso de su «potestad económica». En concreto, no se consideraba conveniente proceder a la ocupación de las temporalidades del vicario de Ayora y del Vicario General del obispado de Orihuela, como había propuesto la Junta del tabaco el 9 de enero de 1731. Sería suficiente, en su opinión, con el cese del vicario de Ayora; la amonestación al Vicario General por «...la poca reflexión y ligereza con que ha procedido en estas diligencias...»; y la advertencia al obispo de Orihuela para que «...zele sobre todos sus ministros para que en sus procedimientos no alteren ni ofendan las regalías de Vuestra Majestad, dando lugar a que se turbe el sosiego público y se sigan escandalosos ruidos...». Pero tampoco la Audiencia de Valencia salía bien parada del conflicto, ya que se le debía reconvenir a que procediese con mucha cautela y precisión en los conflictos que se suscitasen con la jurisdicción eclesiástica, «...sin confundir los casos en que se deben despachar monitorios con citación al vanco regio con los que se han de determinar por contención...». Sin embargo, Felipe V no estaba dispuesto a tener tantas contemplaciones, y el 23 de julio de 1731 dispuso que, aparte de las amonestaciones y advertencias indicadas al Vicario General y el obispo de Orihuela, se procediese a la ocupación de temporalidades y la expulsión del vicario de Ayora, medida que se ejecutó el 5 de agosto posterior, cuando embarcó en Alicante con la advertencia de que «...no vuelva a entrar, ni entre en ellos (los dominios reales), sin expresa licencia de $\mathrm{Su}$ Majestad...» ${ }^{22}$. Nuevamente se resolvía el conflicto con la adopción de una disposición terminante que ponía de manifiesto la vo-

22 A.H.N. Consejos. Leg. 6824. Exp. Nº 17. 
luntad de no seguir tolerando los frecuentes desafíos que planteaba el clero valenciano tanto a las regalías de la Corona como, en última instancia, a la propia autoridad real. No obstante, su reiteración revela la obstinación con la que los miembros del citado estamento defendían unos derechos que consideraban que habían sido gravemente lesionados por el reforzamiento del poder real derivado de la Guerra de Sucesión. De ahí que, si bien los enfrentamientos abiertos fueron cada vez menos frecuentes, la resistencia larvada a las regalías reales se mantuvo durante buena parte del resto de la centuria. 